\title{
Tratamiento con oligonucleótidos antisentido en la enfermedad de Duchenne
}

\author{
Samuel I. Pascual-Pascual
}

Resumen. Se revisa el estado actual de los tratamientos de modificación del ARN de distrofina, que persiguen convertir la forma grave de la distrofia muscular de Duchenne a una forma leve (Becker), especialmente con la omisión del exón 51 mediante oligonucleótidos en antisentido y la terapia de restauración de la lectura de la distrofina, suprimiendo un codón de terminación prematura mediante PTC124. Constituyen un avance notable en el tratamiento. Consiguen una producción significativa de distrofina en el músculo esquelético, aunque, por el momento, los resultados clínicos son menos notables. Es de esperar que modificaciones químicas en la liberación y distribución corporal, así como en la captación celular de estos oligonucleótidos, aumenten su eficacia y seguridad, permitiendo el tratamiento crónico de la distrofia muscular de Duchenne.

Palabras clave. Distrofia muscular de Duchenne. Distrofina. Oligonucleótidos en antisentido.

\section{Introducción}

La distrofia muscular de Duchenne (DMD) es una enfermedad recesiva ligada al cromosoma $\mathrm{X}$ que afecta a $1 / 3.500$ varones. Se debe a la ausencia o déficit subtotal de distrofina, una proteína de $427 \mathrm{kDa}$ que está ubicada en el citoplasma de la célula muscular y que es necesaria para mantener la estabilidad mecánica de la célula y su anclaje a la matriz extracelular. Está unida en su extremo carboxiterminal a otras proteínas de la membrana sarcolémica (complejo distrofino-glucoproteico) y, en el otro extremo, el terminal-N, a las estructuras contráctiles. La parte central de la distrofina (rod domain) conecta ambos extremos. La distrofina actúa, por tanto, de amortiguador de la fuerza contráctil, de modo que los movimientos bruscos de actina-miosina no alteren la membrana muscular. La ausencia de esta proteína conduce a necrosis y apoptosis de la fibra, y produce debilidad progresiva del paciente [1]. Niveles del 30\% de distrofina son suficientes para evitar la distrofia muscular en el humano [2].

La alteración genética de la enfermedad de Duchenne se debe a mutaciones del gen $D M D$, que consta de 79 exones y 2,6 millones de pares de bases. Estas mutaciones corresponden en un $60 \%$ a deleciones, un $6 \%$ son duplicaciones y el resto son mutaciones puntuales [3]. El gen tiene puntos calientes: el 50\% de todas las deleciones afecta a uno o más exones entre el 45 y 53 , y el $20 \%$ asienta entre los exones 2 y 20.
La alteración de este gen produce un amplio espectro de gravedad clínica, desde la más importante, la DMD, hasta la hiperCKemia asintomática, pasando por la distrofia muscular de Becker (DMB), que se expresa como debilidad moderada de cinturas.

La DMD produce síntomas habitualmente antes de los 3-4 años, con debilidad progresiva, que conduce a la pérdida de la marcha autónoma hacia los 10-12 años y complicaciones respiratorias y cardíacas (miocardiopatía) en la segunda década, responsables del fallecimiento del paciente.

La expresión clínica como DMD o como DMB se debe, la mayor parte de las veces, a la pérdida o conservación de la pauta de lectura del gen. Las mutaciones que alteran el marco de lectura producen una proteína truncada, no funcional, carente del C-terminal, y dan lugar al fenotipo DMD, mientras que las que no alteran la pauta de lectura producen una proteína a la que le faltan ciertos aminoácidos, pero que conserva suficiente función, especialmente manteniendo los dominios $\mathrm{N}$ y $\mathrm{C}$, como para producir un fenotipo más leve (DMB) [4]. Deleciones relativamente grandes que asientan en regiones centrales del gen pueden mantener una aceptable funcionalidad [5]. No siempre es así. Hay casos atípicos que, a pesar de deberse a mutaciones que causan pérdida del marco de lectura, producen fenotipo leve (DMB), y esto puede deberse a que alteran la eficiencia del ensamblaje del ARN (splicing) y facilitan la exclusión de un exón, permitiendo mantener la pauta de lectura del gen $[6,7]$.
Servicio de Neurología Pediátrica. Hospital Universitario La Paz. Universidad Autónoma de Madrid. Madrid, España.

Correspondencia:

Dr. Samuel Ignacio Pascual Pascual. Servicio de Neurología Pediátrica. Hospital Universitario La Paz. Paseo de la Castellana, 261. E-28046 Madrid.

E-mail:

sipascual@telefonica.net

Declaración de intereses: El autor no ha recibido patrocinio, beca $u$ honorarios por actividades relacionadas con esta enfermedad o de la industria farmacéutica relacionada con ella. El autor participa como investigador principal en el ensayo clínico de fase III multicéntrico DMD114044 sobre tratamiento de la distrofia muscular de Duchenne con GSK2402968.

Aceptado: 13.04.12.

Cómo citar este artículo: Pascual-Pascual SI. Tratamiento con oligonucleótidos antisentido en la enfermedad de Duchenne. Rev Neurol 2012; 54 (Supl 3): S31-9. 
Hasta la fecha, no se dispone de ningún tratamiento para frenar la progresión de la DMD. El tratamiento es paliativo, mediante terapias físicas y ortopédicas. La intervención farmacológica con glucocorticoesteroides mejora parcial y temporalmente la evolución, pero sin cambiar las características de enfermedad gravemente discapacitante y, en última instancia, mortal.

Se están desplegando estrategias de transferencias génicas mediadas por virus. Dado que el tamaño del gen $D M D$ excede la capacidad de los virus adenoasociados portadores $(4,5 \mathrm{~kb})$, se han desarrollado microgenes de hasta $4 \mathrm{~kb}$ que consiguen grados variables de éxito en el ratón $\mathrm{mdx}$ [8-11], permitiendo entrever resultados futuros. Ya hay algunos ensayos en marcha [12] (http://www.clinicaltrials.gov).

La dificultad principal de la terapia génica en la DMD es, además del gran tamaño del gen $D M D$, que limita las posibilidades de introducción de un fragmento moderadamente funcional de él, la respuesta inmunológica del huésped al vector introducido.

Además de estas estrategias, se están desarrollando otras dirigidas hacia el ARN.

Aproximadamente el 15\% de todos los cambios de ADN implicados en enfermedades humanas causa alguna forma de alteración del ensamblaje del ARN (splicing) [13,14]. Un splicing anormal puede estar causado por cambios de ADN exónicos o intrónicos que pueden excluir a un exón y activar sitios de splicing alternativos en el intrón que incluyan secuencias intrónicas, excluyan secuencias exónicas o generen transcritos anormales. Variaciones de nucleótidos que no afectan directamente a la secuencia de codificación proteica pueden alterar el patrón de ensamblaje, dando lugar a la expresión de fenotipos diferentes. Pues bien, se puede forzar desde fuera a los splicesomas para cambiar secuencias durante el proceso de maduración del ARN, con intención de evitar las consecuencias de una mutación genética que cause DMD. La modificación puede consistir en excluir, incluir o cambiar exones en el ARN mensajero (ARNm) mutado. Aunque en teoría esto sería aplicable a prácticamente todos los tipos de mutaciones genéticas, sin embargo, sólo da resultado en algunas. La exclusión de exones (skipping) sólo será de utilidad en aquellos casos en los que la proteína truncada resultante mantenga suficiente funcionalidad para poder corregir los síntomas. La inclusión de exones será útil en aquellas mutaciones que conducen a deleciones del ARNm. Otro modo de tratamiento de la DMD dirigido al ARN es soslayando, durante la traslación ribosomal, la parada de lectura del ARNm consecutiva a un codón de terminación prematura (PTC) [15].

\section{Exclusión de exón}

La exclusión de uno o más exones de un transcrito puede ser catastrófica si altera el marco de lectura o hace perder dominios funcionalmente importantes de la proteína. Pero, en otras situaciones, puede evitar o paliar un defecto. Las condiciones que hacen que una enfermedad genética pueda beneficiarse del exon skipping son:

- Que el gen se componga de muchos exones y permita la exclusión de algunos sin que la función de la proteína se altere de modo importante.

- Que el transcrito y su proteína tengan una vida media larga, de modo que no haya que administrar continuamente el fármaco para mantener la exclusión.

- Que el tejido o las células que hay que tratar tengan un lento turnover, de modo que el producto del gen modificado pueda persistir,

- Que la proteína modificada no induzca una respuesta inmune.

El gen $D M D$ tiene todas estas características. Posee 79 exones, se expresa principalmente en células musculares y en el cerebro, tejidos de lenta regeneración, el acortamiento de la proteína puede mantener en gran parte su actividad, y la proteína modificada no induce respuesta inmune [16].

La mayoría de las mutaciones del gen $D M D(75 \%)$ puede mejorar con exclusión de algún exón [17]. No se beneficiarán probablemente las que asientan en el promotor, las que afectan a dominios N-terminal o C-terminal que anclan la distrofina a la actina o al sarcolema, o las que producen extensas deleciones, de más de 36 exones [18].

La exclusión de un exón específico puede conseguirse mediante el uso de oligonucleótidos antisentido (OAS) a sitios del ARNm primario. Los OAS alteran el ensamblaje del pre-ARNm, omitiendo el exón en cuestión en el ARNm maduro. Esta omisión se ha demostrado que puede restaurar la pauta de lectura del gen en mioblastos cultivados de pacientes con DMD y en modelos animales.

Puesto que lo deseable es mantener el transcripto modificado, se necesita usar oligonucleótidos que no sean degradados por las endonucleasas. Esto se consiguió al unirlos a 2'O-metil-fosforotioato (los llamados 2'O-metilos) y se comprobó en cultivos de músculo de la DMD humana y el modelo del ratón mdx (que tiene una mutación sin sentido en el exón 23). La exclusión del exón 23 por los oximetilos permite conservar el marco de lectura del gen [19]. La unión de oligonucleótidos a fosforodiamidato-morfolino (P-morfolino) permite también la 
persistencia en la célula, por hacerlos altamente resistentes a las endonucleasas. La composición química de los OAS resulta importante para mejorar la afinidad, estabilidad, liberación, biodistribución y toxicidad.

Los modelos animales empleados son el ratón mdx [20] y el perro golden retriever con distrofia muscular [21,22]. El modelo canino ofrece ventajas para traslación al humano, porque la eficacia, biodistribución y toxicidad dependen, entre otras cosas, del tamaño y de la masa muscular del organismo [15].

\section{Inclusión de exón}

Los OAS también pueden usarse para incluir exones. Estos OAS poseen secuencias antisentido que enmascaran silenciadores de splicing de exones o de intrones.

Éste es un método de tratamiento de la atrofia muscular espinal, enfermedad recesiva causada por mutación del gen SMN1. El gen SMN2 es homólogo al $S M N 1$, sólo difieren en 11 nucleótidos, que inducen la pérdida del exón 7 y lo hacen no funcional [23,24]. La inclusión del exón 7 que se consigue mediante OAS mejora el fenotipo de la atrofia muscular espinal en el ratón $[15,25,26]$.

\section{Cambios de un exón por otro en el ensamblaje del pre-ARNm (spliceosome-mediated RNA trans-splicing)}

Se consiguen mediante la introducción de una molécula exógena que provoca un cambio de ensamblaje. Hasta el momento, el trans-splicing se ha empleado en la atrofia muscular espinal [27] y en la distrofia miotónica de Steinert [15].

\section{Modulación de la translación del ARNm}

Aparte de la intervención en el ARNm, también puede intervenirse en la translación, mediante la inserción de un aminoácido en el codón stop que permita recuperar la lectura del ARN y la formación de la proteína [28].

Alrededor del 13-15\% de los pacientes con DMD tienen una mutación sin sentido en el gen. Esta mutación introduce un codón de parada prematuro en el ARNm que causa el cese en la síntesis de la distrofina, y ésta no será funcional.

Entre las cuatro estrategias citadas, dos han alcanzado el estadio de ensayos clínicos en pacientes con DMD: la exclusión de exón usando OAS, y sortear la finalización de la lectura de ARN debida a un codón stop usando gentamicina o PTC124. Los estudios sobre estos dos métodos, los datos actuales y expectativas en la enfermedad de Duchenne son los que se van a comentar a continuación.

\section{Omisión de exón mediante oligonucleótidos antisentido en la DMD}

La omisión de exón inducida por los OAS es, probablemente, la estrategia terapéutica más alentadora en la actualidad para la DMD [29], y hasta la fecha la DMD es el objetivo primario de tal estrategia.

Hace ya más de tres décadas que Zamecnik y Stephenson [30] publicaron el uso de OAS como posible modo de modificación de la expresión de los genes, pero sólo se avanzó en su uso terapéutico cuando se pudieron desarrollar transformaciones químicas que los hicieran resistentes a su degradación por nucleasas.

Los OAS son pequeñas moléculas sintéticas de 20-30 bases que se adhieren a las secuencias complementarias del exón que se quiere omitir y que bloquean la inclusión de éste en el ARNm. Esta omisión exónica puede permitir la restauración del marco de lectura y la síntesis de distrofina nueva, parcialmente funcional, con la teórica conversión del fenotipo grave de DMD a un fenotipo más leve de DMB. Si los aminoácidos excluidos mediante la omisión del exón son parte de regiones no esenciales, como la parte central de la proteína, el rod domain, se conserva todavía su papel estabilizador en la membrana muscular. La eficacia de los OAS está influenciada por la capacidad de liberación, de distribución sistémica y de persistencia celular, y por el grado de especificidad de su unión a la diana propuesta [13,31].

Para las primeras pruebas de omisión de exón se usaron dos clases de OAS químicamente protegidos para no ser degradados por endonucleasas: los 2'O-metilos y los morfolinos.

El OAS 2'O-metilo utilizado, inicialmente llamado PRO051 y posteriormente GSK2402968, tiene la secuencia de bases: UCUUUACGGUAGAAGGAACU, y el morfolino, llamado AVI-4658, tiene la secuencia GAUCUUUACGGUAGAAGGAACUACAACCUC, que engloba a la del 2'O-metilo. Ambos OAS se unen a la secuencia potenciadora del empalme-exónica en el exón 51. Al bloquear la secuencia, se omite el exón 51 en el ARNm.

Para que se alcance beneficio práctico, es necesario que el agente penetre en los núcleos de las fi- 
bras musculares y que no sea tóxico en dosis suficientes como para permitir la distribución corporal extensa. Se comprobó que el oligonucleótido 2'Ometilo podía restaurar la producción de proteína en cultivo de células del ratón mdx [32]. Se ha demostrado la amplia distribución corporal [33], pero con resultado irregular en diferentes músculos y sin conseguir producción sustancial de distrofina en el miocardio [34]. El OAS morfolino también activa la producción de distrofina en múltiples músculos del ratón mdx [35]. En el modelo canino, consigue formar distrofina nueva en proporción hasta del $50 \%$ en algunos músculos, que es funcionalmente útil. Un perro tratado se mantuvo sin deterioro a lo largo del tratamiento, a diferencia de lo observado en los perros no tratados [36].

Se han encontrado diferencias entre ambos OAS en el modelo del ratón $\mathrm{mdx}$, en el que omiten el exón 23, pero estas diferencias son mínimas contra exones humanos inyectados a ratones [37]. Se ha referido una resistencia a endonucleasas más prolongada y mayor afinidad a la secuencia diana con P-morfolino [38]. Es posible que unos exones puedan ser omitidos mejor con uno u otro OAS.

Se han creado OAS para todos los exones de la DMD $[39,40]$, cada uno con una estructura que bloquea sólo el exón diana, sin afectar a ningún otro en los genes humanos.

En función de dónde asienta la deleción del gen $D M D$, será distinto el exón o exones a excluir. La omisión del exón 51 es aplicable al 13\% de las DMD; la omisión del exón 45 , al 8,1\%, y otras omisiones pueden constituir el tratamiento de una menor proporción de DMD [40].

Las posibilidades teóricas de aplicación de la omisión de exón son del $64 \%$ de todos los pacientes con DMD [40].

La terapia con AOS también puede ser útil en otras enfermedades neuromusculares, como la distrofia muscular de cinturas debida a déficit de disferlina. El amplio espectro de gravedad según los exones delecionados sugiere que puede mantenerse una función parcial de la disferlina delecionada [41].

Los P-morfolinos pueden unirse a péptidos penetrantes en células o a grupos de octaguanidina para mejorar la liberación sistémica y la penetración en el músculo esquelético y cardíaco [42]. Por el momento, la seguridad de estos compuestos modificados no se ha demostrado en humanos [43]. Sólo los OAS no modificados están probándose en ensayos clínicos, y se ha demostrado seguridad y eficiencia de 2'OMePS y de P-morfolinos dirigidos contra el exón 51 en inyección sistémica en pacientes con DMD [44].

\section{Doble omisión y multiomisión de exón}

Muchos de de los casos de DMD causadas por deleciones, duplicaciones y mutaciones puntuales necesitarán la omisión de dos o más exones para restaurar el marco de lectura.

Por consideraciones teóricas, se prevé incluso que la omisión simultánea de los 11 exones que van del 45 al 55 produce una distrofia de Becker con síntomas muy leves hasta en el 63\% de los niños con Duchenne [45]. Se ha probado la omisión de estos 11 exones en mioblastos de una persona sana y en dos pacientes con DMD, pero no se lograron más que niveles bajos de distrofina, por lo que, en la actualidad, todavía no es clínicamente útil [46].

Se han realizado intentos de omisión multiexón usando 2'OMePS-OAS en células de pacientes con DMD que no han sido concluyentes, pero un cóctel de tres P-mordolinos por vía intravenosa tuvo éxito en el modelo canino, llegando a producir distrofina funcionalmente útil [36]. Esta discrepancia sugiere que la eficiencia de multiexon skipping puede ser difícil de lograr, y podría depender de la química de los OAS y de las secuencias diana.

\section{Estudios realizados en humanos con DMD con OAS}

\section{GSK2402968}

El GSK2402968 (antes denominado PRO051) es un 2'OMePS dirigido contra el exón 51. Numerosos estudios no clínicos han probado que induce la producción de distrofina nueva en células musculares cultivadas de una serie de pacientes con DMD con diferentes mutaciones, en modelos de ratones $\mathrm{mdx}$ y transgénicos de DMD humana, y en el modelo canino de DMD [47-51].

Un primer estudio en humanos de fase I/II con PRO051/GSK2402968 para probar la utilidad de producir distrofina nueva, la seguridad y la tolerabilidad del compuesto en dosis de $0,8 \mathrm{mg} / \mathrm{kg}$ administrada por vía intramuscular en cuatro pacientes con DMD con deleciones del exón 50 o 52, o de los exones 45-50, 48-50 o 49-50 (que son los que pueden corregir la pauta de lectura al omitir el exón 51), demostró que tras cuatro semanas con una inyección semanal en el músculo tibial anterior se restauraba distrofina nueva en el 64-97\% de las fibras en el área inyectada. En comparación con la laminina $\alpha 2$, una proteína no afectada por el proceso distrófico, el contenido de distrofina fue del 17-35\%. El tratamiento fue muy bien tolerado [52].

En un estudio posterior abierto, de fase I/IIa, para conocer el rango de seguridad de la dosis, el producto PRO051/GSK2402968 se administró sub- 
cutáneamente durante cinco semanas a 12 pacientes en dosis múltiples, en aumento, 0,5-6 mg/kg. En cada grupo de dosis, tres sujetos recibieron cinco inyecciones a intervalos semanales. El estudio demostró buena tolerabilidad y detección de distrofina nueva en todos los pacientes [53]. Se detectó la expresión de distrofina nueva en todos los grupos de dosis, siendo mayor en los dos grupos de dosis más alta (4 y $6 \mathrm{mg} / \mathrm{kg}$ ). No se observó mejora de la fuerza, pero el estudio duró únicamente cinco semanas y éste no era el objetivo. La mayoría de los acontecimientos adversos fueron eritema local leve en el lugar de la inyección. No hubo efectos adversos hematológicos ni urinarios ni electrocardiográficos. Tras la inyección subcutánea de GSK2402968, se alcanzaban valores sanguíneos máximos a las 2-3 horas, descendiendo hasta menos del $15 \%$ a las 24 horas. Con la inyección repetida, las concentraciones máximas tendían a aumentar.

Todos los sujetos tratados entraron en la fase de extensión abierta y recibieron, por lo menos, seis meses de tratamiento en dosis de $6 \mathrm{mg} / \mathrm{kg} / \mathrm{semana}$. El fármaco se toleró bien. Sólo se han observado reacciones cutáneas de intensidad leve a moderada, que no impiden continuar con el tratamiento. Los estudios del laboratorio revelaron signos de nefrotoxicidad leve, subclínica (proteinuria leve), que justifican una monitorización cuidadosa. La función motora aumentó un promedio de $36,8 \mathrm{~m}$ (intervalo: $-58 \mathrm{a}+115 \mathrm{~m}$ ) en la prueba de la marcha en 6 minutos. Estos datos se deben interpretar con cautela, debido al número escaso de sujetos y a la naturaleza abierta del estudio.

Hasta la fecha, se conocen los resultados de GSK2402968 administrado a un total de 16 sujetos con DMD en los dos estudios clínicos aludidos, y se están desarrollando otros ensayos (http://www.clinicaltrials.gov).

Un ensayo de fase III (DMD114044) multicéntrico comenzó en 2011 y está desarrollándose en la actualidad. Pretende reclutar 180 pacientes en Europa, Asia, Canadá y Sudamérica. Los objetivos son estudiar la seguridad, la farmacocinética y la eficacia en niños ambulantes con DMD entre 5 y 15 años de edad. No se conocen los resultados.

Otros ensayos clínicos de PRO051/GSK2402968 de fase II se están realizando simultáneamente al anterior. Uno de ellos, el DMD114876, busca evaluar dos dosis (3 mg/ $\mathrm{kg} / \mathrm{semana}$ o $6 \mathrm{mg} / \mathrm{kg} / \mathrm{semana}$ contra placebo) en niños con DMD. Otro estudio, el DMD114117, de fase II doble ciego, controlado con placebo, busca investigar la eficacia de GSK2402968 en dos dosis $(6 \mathrm{mg} / \mathrm{kg} / \mathrm{semana}$ de forma continua y $6 \mathrm{mg} / \mathrm{kg} / \mathrm{semana}$ intermitentemente) y pretende re- clutar 54 casos. Otro más, el DMD114118, busca evaluar, en niños con DMD no ambulantes, la farmacocinética y el efecto de PRO051/GSK2402968 en inyecciones subcutáneas de $6 \mathrm{mg} / \mathrm{kg} / \mathrm{semana}$ continua y $6 \mathrm{mg} / \mathrm{kg} / \mathrm{semana}$ intermitente en comparación con la evolución natural. Está, además, en marcha el ensayo de fase III DMD144349, que es la fase abierta de extensión de los niños con DMD que han entrado en los ensayos DMD114117 y DMD114044 aludidos.

\section{OAS morfolino contra el exón 51}

Un estudio de fase I/II empleando P-morfolino, realizado con siete pacientes con DMD con deleciones de los exones 45-50, 47-50, 48-50, 49-50, 50, 52 o 52-63, a los que se les inyectó P-morfolino (AVI-4658) intramuscular en el músculo extensor corto de los dedos, demostró la seguridad y la producción de distrofina en el 44-79\% de las fibras en el área tratada [44]. Como resultado de ello, se inició otro estudio de fase I/II con resultados publicados recientemente [54]. Fueron reclutados 19 pacientes ambulantes con DMD que recibieron dosis de $0,5,1,2,4,10$ y $20 \mathrm{mg} / \mathrm{kg}$. El fármaco fue bien tolerado, no se presentaron efectos adversos graves. El fármaco indujo la omisión del exón 51 en todos los grupos de dosis, y la expresión de distrofina en proporción relacionada con la dosis inyectada, aunque en cantidad variable. Siete de los 19 pacientes respondieron al tratamiento, con un incremento medio de distrofina tras el tratamiento que alcanzaba el $8,9-16,4 \%$ de la distrofina de los controles. Los tres pacientes con mayores respuestas alcanzaron el 21, 15 y 55\% de fibras distrofinpositivas. Las proteínas asociadas a la distrofina (sarcoglicanos y sintasa de óxido nítrico neuronal) también resultaron restauradas en el sarcolema. Asimismo, se observó reducción de la infiltración inflamatoria.

La cantidad de OAS efectiva por vía sistémica para producir y mantener la producción de distrofina es muy importante, dado que la administración del tratamiento debe ser crónica y dosis acumuladas podrían llegar a ser tóxicas. Se ha mostrado que dosis tan bajas como cuatro inyecciones semanales de $5 \mathrm{mg} / \mathrm{kg}$ de P-morfolino inducen expresión significativa de distrofina en el ratón mdx [55].

Dosis de P-morfolino aplicadas durante un año son seguras en el ratón. Restauran la producción de distrofina tanto en dosis de $5 \mathrm{mg} / \mathrm{kg}$ como de 50 $\mathrm{mg} / \mathrm{kg}$, y el ratón tratado consigue moverse como el animal sano. Sin embargo, como muestran otros estudios, no se observó expresión de distrofina en el músculo cardíaco [56]. 
Por lo tanto, y en resumen, el tratamiento con OAS para inducir exon skipping es prometedor en la DMD, usando tanto 2'O-metilos como morfolinos. No constituye la curación de la enfermedad, sino una disminución de su gravedad. Ya hay datos de resultados a corto plazo en la omisión del exón 51, que es aplicable al 13\% de los pacientes con DMD. Sin embargo, con los compuestos químicos actuales, este efecto sólo es ligeramente útil desde el punto de vista clínico, en especial si no se consigue producir distrofina cardíaca.

Queda pendiente de conocer el modo más eficiente de difundir por toda la musculatura corporal el OAS, especialmente de alcanzar el músculo cardíaco, y la eliminación de la toxicidad a largo plazo. Estos obstáculos pueden reducirse desarrollando nuevos portadores con baja respuesta inmunológica y una mayor biodistribución.

La captación de morfolino mejora con conjugados peptídicos. Así, se consigue expresar distrofina en el ratón $\mathrm{mdx}$, incluso en el miocardio [57], pero un inconveniente es que puede inducir respuesta inmunológica tras inyecciones repetidas. Una modificación del conjugado peptídico de morfolino [58] ha mostrado una importante corrección de distrofina en músculos esqueléticos sin observar respuesta inmunológica, y consigue, además, corregir el fenotipo distrófico, aunque no llega a formar distrofina en el miocardio.

El uso de 2'O-metilos unidos a nanopartículas de polimetilmetacrilato catiónico [59] mejora la penetración en el músculo, necesitando menor dosis de fármaco, lo que disminuye la posibilidad de respuesta inmunológica y de efectos en otras dianas (exones) no deseadas. Asimismo el morfolino conjugado a un portador no peptídico [60,61] muestra un gran potencial para la aplicación terapéutica.

Sigue siendo un misterio por qué la entrada en las fibras musculares es tan variable: unas forman casi la misma distrofina que las células normales, mientras que otras células vecinas prácticamente no forman nada en la inmunotinción. En general, parece depender de propiedades intrínsecas del músculo, ya que la producción de distrofina suele ser similar en los mismos músculos en diferentes ensayos de un mismo protocolo. También parece que el grado de avance de la enfermedad y la alteración de la microvascularización muscular es un factor importante en la entrada del oligonucleótido [5].

Un posible modo de superar estas limitaciones es combinar la terapia OAS con la transferencia genética. Consiste en introducir un plásmido con secuencia antisentido del exón, mediante un virus adenoasociado. De este modo, se ha conseguido for- mar distrofina durante un largo período tras una administración única [62]. Sin embargo, estos vectores inducen respuestas inmunológicas que neutralizan el virus en las readministraciones. Aunque estos problemas no parecen definitivos, han retrasado su aplicación a ensayos humanos de DMD.

Otra duda importante es si estos tratamientos únicamente enlentecen o estabilizan la evolución de la DMD o pueden conseguir algún grado de recuperación de la pérdida muscular. Por el momento, parece que, principalmente, se consigue la estabilización, pero es de esperar que, tratando musculatura sin necrosis ni inflamación importantes, se pueda restaurar algún grado de funcionalidad.

\section{Modulación de la translación del ARN (en los PTC)}

Como ya se ha comentado, además de la intervención en el ARNm, también puede intervenirse en la translación, evitando la parada de lectura del gen consecutiva a una mutación sin sentido. Esta intervención se ha probado en varias enfermedades, incluyendo, entre las neuromusculares, la DMD y la atrofia muscular espinal. Alrededor del 13-15\% de los pacientes con DMD tienen una mutación sin sentido en el gen. Para determinar si un niño con DMD puede beneficiarse de esta estrategia, debe demostrarse la presencia de una mutación de parada prematura (TGA, TAG o TAA) en uno de los exones del gen de la distrofina [63].

Este tipo de tratamiento se ha logrado con antibióticos y con PTC124.

\section{Aminoglucósidos y negamicina}

Los aminoglucósidos son antibióticos que se ligan al ARN ribosomal $18 \mathrm{~S}$ e interfieren con la parada de la traslación, permitiendo continuar la lectura en los PTC [64]. La eficiencia de la restauración de la lectura depende del tipo de PTC. El más eficiente es el UGA, seguido por el UAG y, por último, del UAA [65].

La gentamicina fue el primero en utilizarse [66]. Permitió restaurar el 10-20\% de la distrofina en el modelo murino de DMD tras inyectarla por vía subcutánea [67]. Sin embargo, los aminoglucósidos tienen limitaciones: no tienen especificidad por los PTC, la restauración depende de la naturaleza del codón stop y de la secuencia proximal y, especialmente, su nefro y ototoxicidad.

Para evitar estos problemas, se han examinado otros compuestos, como negamicina, un antibióti- 
co dipeptídico que también altera la translación y consigue incrementar los niveles de distrofina al $10 \%$ de lo normal en los músculos esquelético y cardíaco del ratón mdx, sin toxicidad, aunque no se demostrado su especificidad hacia los PTC, aspecto necesario para probarlo como terapia para pacientes con DMD [68].

\section{PTC124 (Ataluren ${ }^{\circledR}$ )}

Este fármaco no tiene similitud estructural con los aminoglucósidos. Permite restaurar la lectura de los PTC sin afectar a la terminación normal de la lectura de los genes. Usado por vía oral o intraperitoneal, consigue restaurar la lectura e incrementar la distrofina hasta el 20-25\% de lo normal en músculos en el ratón mdx [63]. Este nivel de expresión proteica impide el daño inducido por la contracción muscular y disminuye la CPK sérica en el extensor largo de los dedos en el ratón mdx. Con estos datos, ha pasado a ensayarse en humanos.

Se ha comprobado la seguridad del PTC124 oral en voluntarios sanos (fase I) [69]. Tras ello, se ha realizado un ensayo de fase IIb (NCT00592553) doble ciego, controlado con placebo, para evaluar la seguridad y eficacia de dos dosis, 40 y $80 \mathrm{mg} /$ día, vía oral, durante 48 semanas. El estudio trató a 174 niños ambulantes mayores de 5 años en 37 centros. La medida primaria de eficacia fue el test de la marcha en seis minutos. Otras medidas fueron la fuerza muscular y la expresión de distrofina en biopsias realizadas antes del tratamiento y durante éste. Los resultados no se han publicado, pero los presentados inicialmente indican que el tratamiento es seguro, si bien no hay diferencia significativa en el test de la marcha de 6 minutos entre los grupos tratados y el grupo control [70].

\section{Implicaciones terapéuticas}

Con el crecimiento de nuestro conocimiento de los defectos moleculares en las enfermedades y el desarrollo de instrumentos de modificación del ARN, están emergiendo nuevas estrategias para las enfermedades genéticas y, en concreto, para la DMD. En lo que respecta a la terapia con OAS, el tratamiento es individualizado para cada una de las mutaciones, de modo que es necesario elaborar un registro de todas ellas y de la gravedad de los síntomas que se les asocian. Aquéllas en las que la proteína acortada por omisión de exones siga teniendo actividad podrán beneficiarse de la terapia. El uso de OAS contra los exones $43,44,45,46,50,52$ y 53, además del
51, puede permitir el tratamiento de más del $65 \%$ de las deleciones de la DMD.

Muchas cuestiones de orden práctico quedan por contestarse para acercarnos al uso clínico extenso. ¿Son estas moléculas verdaderamente específicas para el ARN mutado o pueden afectar también a otros genes? ¿Cómo se pueden evitar las respuestas inmunes a portadores peptídicos o a proteínas virales? La terapia de modificación del ARN, ¿será útil en todos los estadios de la enfermedad, o sólo en los iniciales cuando la degeneración tisular todavía no es importante? ¿Se presentará toxicidad a largo plazo dado que el tratamiento se presume como crónico?

Aunque todavía deben vencerse muchos obstáculos, como los de liberación, mantenimiento y especificidad del fármaco por el tejido afectado, se están haciendo grandes progresos en el campo de los tratamientos específicos de la DMD.

\section{Bibliografía}

1. Hoffman EP, Brown RH Jr, Kunkel LM. Dystrophin: the protein product of the Duchenne muscular dystrophy locus. Cell 1987; 51, 919-28.

2. Neri M, Torelli S, Brown S, Ugo I, Sabatelli P, Merlini L, et al. Dystrophin levels as low as 30\% are sufficient to avoid muscular dystrophy in the human. Neuromuscul Disord 2007; 17: 913-8.

3. Aartsma-Rus A, van Deutekom JC, Fokkema IF, Van Ommen GJ, Den Dunnen JT. Entries in the Leiden Duchenne muscular dystrophy mutation database: an overview of mutation types and paradoxical cases that conform the reading-frame rule. Muscle Nerve 2006; 135-44.

4. Monaco AP, Bertelson CJ, Liechti-Gallati S, Moser H. Kunkel LM. An explanation for the phenotypic differences between patients bearing partial deletions of the DMD locus. Genomics 1988; 2: 90-5.

5. Partridge T. The potential of exon skipping for treatment for Duchenne muscular dystrophy. J Child Neurol 2010; 25: 1165-70.

6. Shiga N, Takeshima Y, Sakamoto H, Inoue K, Yokota Y, Yokoyama M, et al. Disruption of the splicing enhancer sequence within exon 27 of the dystrophin gene by a nonsense mutation induces partial skipping of the exon and is responsible for Becker muscular dystrophy. J Clin Invest 1997; 100: 2204-10.

7. Ginjaar IB, Kneppers AL, Van der Meulen JD, Anderson LV, Bremmer-Bout M, Van Deutekom JC, et al. Dystrophin nonsense mutation induces different levels of exon 29 skipping and leads to variable phenotypes within one BMD family. Eur J Hum Genet 2000; 8: 793-6.

8. Townsend D, Blankinship MJ, Allen JM, Gregorevic P, Chamberlain JS, Metzger JM. Systemic administration of micro-dystrophin restores cardiac geometry and prevents dobutamine-induced cardiac pump failure. Mol Ther 2007; 15: 1086-92.

9. Wang Z, Kuhr CS, Allen JM, Blankinship M, Gregorevic P, Chamberlain JS, et al. Sustained AAV-mediated dystrophin expression in a canine model of Duchenne muscular dystrophy with a brief course of immunosuppression. Mol Ther 2007; 15: 1160-6.

10. Gregorevic P, Blankinship MJ, Allen JM, Chamberlain JS. Systemic microdystrophin gene delivery improves skeletal muscle structure and function in old dystrophic mdx mice. Mol Ther 2008; 66: 657-64.

11. McNeil DE, Davis C, Jillapalli D, Targum S, Durmowicz A, Coté TR. Duchenne muscular dystrophy: drug development and regulatory considerations. Muscle Nerve 2010; 41: 740-5. 
12. Odom GL, Banks GB, Schultz BR, Gregorevic P, Chamberlain JS. Preclinical studies for gene therapy of Duchenne muscular dystrophy. J Child Neurol 2010; 25: 1149-57.

13. Wilton SD, Fletcher S. RNA Splicing manipulation: strategies to modify gene expression for a variety of therapeutic outcomes. Curr Gene Ther 2011; 11: 259-75.

14. Hastings ML, Krainer AR. Pre-mRNA splicing in the new millennium. Curr Opin Cell Biol 2001; 13: 302-9.

15. Le Roy F, Charton K, Lorson CL, Richard I. RNA-targeting approaches for neuromuscular diseases. Trends Mol Med 2009; 15: 580-91.

16. Wilton S, Dye DE, Laing NG. Dystrophin gene transcripts skipping the mdx mutation. Muscle Nerve 1997; 20: 728-34.

17. Aartsma-Rus A, Janson AA, Kaman WE, Bremmer-Bout M, Van Ommen GJ, Den Dunnen JT, et al. Antisense-induced multiexon skipping for Duchenne muscular dystrophy makes more sense. Am J Hum Genet 2004; 74: 83-92.

18. Fanin M, Freda MP, Vitiello L, Danieli GA, Pegoraro E, Angelini C. Duchenne phenotype with in-frame deletion removing major portion of dystrophin rod: threshold effect for deletion size? Muscle Nerve 1996; 19: 1154-60.

19. Sicinski P, Geng Y, Ryder-Cook AS, Barnard EA, Darlison MG, Barnard PJ. The molecular basis of muscular dystrophy in the mdx mouse: a point mutation. Science $1989 ; 244: 1578-80$

20. Bulfield G, Siller WG, Wight PA, Moore KJ. X chromosome linked muscular dystrophy (mdx) in the mouse. Proc Natl Acad Sci U S A 1984; 81: 1189-92.

21. Kornegay JN, Tuler SM, Miller DM, Levesque DC. Muscular dystrophy in a litter of golden retriever dogs. Muscle Nerve 1988; 11: 1056-64.

22. Cooper BJ, Winand NJ, Stedman H, Valentine BA, Hoffman EP, Kunkel LM, et al. The homologue of the Duchenne locus is defective in X-linked muscular dystrophy of dogs. Nature 1988; 334: 154-6.

23. Lefebvre S, Bürglen L, Reboullet S, Clermont O, Burlet P, Viollet L, et al. Identification and characterization of a spinal muscular atrophy-determining gene. Cell 1995; 80: 155-65.

24. Monani UR, Lorson CL, Parsons DW, Prior TW, Androphy EJ, Burghes AH, et al. A single nucleotide difference that alters splicing patterns distinguishes the SMA gene SMN1 from the copy gene SMN2. Hum Mol Genet 1999; 8: 1177-83.

25. Dickson A, Osman E, Lorson CL. A negatively acting bifunctional RNA increases survival motor neuron both in vitro and in vivo. Hum Gene Ther 2008; 19: 1307-15.

26. Williams JH, Schray RC, Patterson CA, Ayitey SO, Tallent MK, Lutz GJ. Oligonucleotide-mediated survival of motor neuron protein expression in CNS improves phenotype in a mouse model of spinal muscular atrophy. J Neurosci 2009 29: 7633-8.

27. Coady TH, Shababi M, Tullis GE, Lorson CL. Restoration of SMN function: delivery of a trans-splicing RNA re-directs SMN2 pre-mRNA splicing. Mol Ther 2007; 15: 1471-8.

28. Linde L, Kerem B. Introducing sense into nonsense in treatments of human genetic diseases. Trends Genet 2008; 24: 552-63.

29. Van Ommen GJ, Van Deutekom J, Aartsma-Rus A. The therapeutic potential of antisense-mediated exon skipping. Curr Opin Mol Ther 2008; 10: 140-9.

30. Zamecnik PC, Stephenson ML. Inhibition of Rous sarcoma virus replication and cell transformation by a specific oligodeoxynucleotide. Proc Natl Acad Sci U S A 1978; 75: 280-4.

31. Van Oekelen D, Luyten WH, Leysen JE. Ten years of antisense inhibition of brain G-protein-coupled receptor function. Brain Res Rev 2003; 42: 123-42.

32. Mann CJ, Honeyman K, Cheng AJ, Ly T, Lloyd F, Fletcher S, et al. Antisense-induced exon skipping and synthesis of dystrophin in the mdx mouse. Proc Natl Acad Sci U S A 2001; 98: 42-7.

33. Lu QL, Mann CJ, Lou F, Bou-Gharios G, Morris GE, Xue SA, et al. Functional amounts of dystrophin produced by skipping the mutated exon in the mdx dystrophic mouse. Nat Med 2003; 9: 1009-14.

34. Lu QL, Rabinowitz A, Chen YC, Yokota T, Yin H, Alter J, et al.
Systemic delivery of antisense oligoribonucleotide restores dystrophin expression in bodywide skeletal muscles. Proc Natl Acad Sci U S A 2005; 102: 198-203.

35. Alter J, Lou F, Rabinowitz A, Yin H, Rosenfeld J, Wilton SD, et al. Systemic delivery of morpholino oligonucleotide restores dystrophin expression bodywide and improves dystrophic pathology. Nat Med 2006; 12: 175-7.

36. Yokota T, Lu QL, Partridge T, Kobayashi M, Nakamura A Takeda S, et al. Efficacy of systemic morpholino exon-skipping in Duchenne dystrophy dogs. Ann Neurol 2009; 65: 667-76.

37. Heemskerk HA, De Winter CL, De Kimpe SJ, Van KuikRomeijn P, Heuvelmans N, Platenburg GJ, et al. In vivo comparison of 2'-O-methyl phosphorothioate and morpholino antisense oligonucleotides for Duchenne muscular dystrophy skipping. J Gene Med 2009; 11: 257-66.

38. Popplewell LJ, Trollet C, Dickson G, Graham IR. Design of phosphorodiamidate morpholino oligomers (PMOs) for the induction of exon skipping of the human DMD gene. Mol Ther 2009; 17: 554-61.

39. Wilton SD, Fall AM, Harding PL, McClorey G, Coleman C, Fletcher S. Antisense oligonucleotide-induced exon skipping across the human dystrophin gene transcript. Mol Ther 2007; $15 ; 1288-96$.

40. Aartsma-Rus A, Fokkema I, Verschuuren J, Ginjaar I, Van Deutekom J, Van Ommen GJ, et al. Theoretic applicability of antisense-mediated exon skipping for Duchenne muscular dystrophy mutations. Hum Mutat 2009; 30; 293-9.

41. Aartsma-Rus A, Singh KH, Fokkema IF, Ginjaar IB, Van Ommen GJ, Den Dunnen JT, et al. Therapeutic exon skipping for dysferlinopathies? Eur J Hum Genet 2010; 18: 889-94.

42. Wu B, Li Y, Morcos PA, Doran TJ, Lu P, Lu QL. Octa-guanidine morpholino restores dystrophin expression in cardiac and skeletal muscles and ameliorates pathology in dystrophic mdx mice. Mol Ther 2009; 17: 864-71.

43. Moulton HM, Moulton JD. Morpholinos and their peptide conjugates: therapeutic promise and challenge for Duchenne muscular dystrophy. Biochim Biophys Acta 2010; 1798: 2296-303.

44. Kinali M, Arechavala-Gomeza V, Feng L, Cirak S, Hunt D, Adkin C, et al. Local restoration of dystrophin expression with the morpholino oligomer AVI-4658 in Duchenne muscular dystrophy: a single-blind, placebo-controlled, dose-escalation, proof-of-concept study. Lancet Neurol 2009; 8: 918-28.

45. Béroud C, Tuffery-Giraud S, Matsuo M, Hamroun D, Humbertclaude V, Monnier N, et al. Multiexon skipping leading to an artificial DMD protein lacking amino acids from exons 45 through 55 could rescue up to $63 \%$ of patients with Duchenne muscular dystrophy. Hum Mutat 2007; 28: 196-202.

46. Van Vliet L, De Winter C, Van Deutekom JCT, Van Ommen GJ, Aartsma-Rus A. Assessment of the feasibility of exon 45-55 multiexon skipping for Duchenne muscular dystrophy. BMC Med Genet 2008; 9: 105.

47. Aartsma-Rus A, Janson AA, Kaman WE, Bremmer-Bout M, Den Dunnen JT, Baas F, et al. Therapeutic antisense-induced exon skipping in cultured muscle cells from six different DMD patients. Hum Mol Genet 2003; 12: 907-14.

48. Aartsma-Rus A, Kaman WE, Bremmer-Bout M, Janson AA, Den Dunnen JT, Van Ommen GJ, et al. Comparative analysis of antisense oligonucleotide analogs for targeted DMD exon 46 skipping in muscle cells. Gene Ther 2004; 11: 1391-8.

49. Bremmer-Bout M, Aartsma-Rus A, De Meijer EJ, Janson AA, Vossen RH, Van Ommen GJ, et al. Targeted exon skipping in transgenic hDMD mice: a model for direct preclinical screening of human-specific antisense oligonucleotides. Mol Ther 2004; 10: 232-40.

50. Lu QL, Mann CJ, Lou F, Bou-Gharios G, Morris GE, Xue SA, et al. Functional amounts of dystrophin produced by skipping the mutated exon in the mdx dystrophic mouse. Nat Med 2003; 9: 1009-14.

51. Yokota T, Takeda S, Lu QL, Partridge TA, Nakamura A, Hoffman EP. A renaissance for antisense oligonucleotide drugs in neurology: exon skipping breaks new ground. Arch Neurol 2009; 66: 32-8.

52. Van Deutekom JC, Janson AA, Ginjaar IB, Frankhuizen WS, 
Aartsma-Rus A, Bremmer-Bout M, et al. Local dystrophin restoration with antisense oligonucleotide PRO051. N Engl J Med 2007; 357: 2677-86.

53. Goemans NM, Tulinius M, Van den Akker JT, Burm BE, Ekhart PF, Heuvelmans N, et al. Systemic administration of PRO051 in Duchenne's muscular dystrophy. N Engl J Med 2011; 364: 1513-22.

54. Cirak S, Arechavala-Gomeza V, Guglieri M, Feng L, Torelli S, Anthony K, et al. Exon skipping and dystrophin restoration in patientswith Duchenne muscular dystrophy after systemic phosphorodiamidate morpholino oligomer treatment: an open-label, phase 2, dose-escalation study. Lancet 2011; 378: 595-605.

55. Malerba A, Thorogood FC, Dickson G, Graham IR. Dosing regimen has a significant impact on the efficiency of morpholino oligomer-induced exon skipping in mdx mice. Hum Genet Ther 2009; 20: 955-65.

56. Malerba A, Sharp PS, Graham IR, Arechavala-Gomeza V, Foster K, Muntoni F, et al. Chronic systemic therapy with low-dose morpholino oligomers ameliorates the pathology and normalizes locomotor behavior in $\mathrm{mdx}$ mice. Mol Ther 2011; 19: 345-54.

57. Jearawiriyapaisarn N, Moulton HM, Buckley B, Roberts J, Sazani P, Fucharoen S, et al. Sustained dystrophin expression induced by peptide-conjugated morpholino oligomers in the muscles of mdx mice. Mol Ther 2008; 16: 1624-9.

58. Yin H, Moulton HM, Betts C, Merritt T, Seow Y, Ashraf S, et al. Functional rescue of dystrophin-deficient mdx mice by a chimeric peptide-PMO. Mol Ther 2010; 18: 1822-9.

59. Rimessi P, Sabatelli P, Fabris M, Braghetta P, Bassi E, Spitali P, et al. Cationic PMMA nanoparticles bind and deliver antisense oligoribonucleotides allowing restoration of dystrophin expression in the mdx mouse. Mol Ther 2009; 17: 820-7.

60. Wu B, Li Y, Morcos PA, Doran TJ, Lu P, Lu QL, et al. Octa-guanidine morpholino restores dystrophin expression in cardiac and skeletal muscles and ameliorates pathology in dystrophic mdx mice. Mol Ther 2009; 17: 864-71.
61. Wu B, Moulton HM, Iversen PL, Jiang J, Li J, Spurney CF, et al. Effective rescue of dystrophin improves cardiac function in dystrophin-deficient mice by a modified morpholino oligomer. Proc Natl Acad Sci U S A 2008; 105: 14814-9.

62. Goyenvalle A, Vulin A, Fougerousse F, Leturcq F, Kaplan JC García L, et al. Rescue of dystrophic muscle through U7 snRNA-mediated exon skipping. Science 2004; 306: 1796-9.

63. Welch EM, Barton ER, Zhuo J, Tomizawa Y, Friesen WJ, Trifillis P, et al. PTC124 targets genetic disorders caused by nonsense mutations. Nature 2007; 447: 87-91.

64. Hermann T. Aminoglycoside antibiotics: old drugs and new therapeutic approaches. Cell Mol Life Sci 2007; 64: 1841-52.

65. Howard MT, Shirts BH, Petros LM, Flanigan KM, Gesteland RF, Atkins JF. Sequence specificity of aminoglycoside-induced stop codon readthrough: potential implications for treatment of Duchenne muscular dystrophy. Ann Neurol 2000; 48: 164-9.

66. Wagner KR, Hamed S, Hadley DW, Gropman AL, Burstein AH, Escolar DM, et al. Gentamicin treatment of Duchenne and Becker muscular dystrophy due to nonsense mutations. Ann Neurol 2001; 49: 706-11.

67. Barton-Davis ER, Cordier L, Shoturma DI, Leland SE, Sweeney HL. Aminoglycoside antibiotics restore dystrophin function to skeletal muscles of mdx mice. J Clin Invest 1999; 104: 375-81.

68. Arakawa M, Shiozuka M, Nakayama Y, Hara T, Hamada M, Kondo S, et al. Negamycin restores dystrophin expression in skeletal and cardiac muscles of mdx mice. J Biochem 2003; 134: 751-8.

69. Hirawat S, Welch EM, Elfring GL. Safety, tolerability, and pharmacokinetics of PTC124, a nonaminoglycoside nonsense mutation suppressor, following single- and multiple-dose administration to healthy male and female adult volunteers. J Clin Pharmacol 2007; 47: 430-44.

70. Finkel RS. Read-through strategies for suppression of nonsense mutations in Duchenne/Becker muscular dystrophy: aminoglycosides and Ataluren (PTC124). J Child Neurol 2010; 25: 1158-64.

\section{Treatment with antisense oligonucleotides in Duchenne's disease}

Summary. In this paper I review the results of the treatments directed to modify the mRNA of dystrophin with the goal of converting the severe Duchenne type to the milder Becker muscular dystrophy. Antisense oligomers potential to modify Duchenne muscular dystrophy (DMD) gene expression and therapeutic strategies to induce ribosomal read-through of nonsense mutations (PTC124) are described. They are an important advance in the treatment of DMD, so far unspecific. Significant expression of new dystrophin is observed in biopsies of peripheral muscle, although the functional improvement is not so encouraging. New modification of chemistries are expected to improve the liberation, broad distribution in muscles, as well as their efficacy and safety enough to allow a positive chronic treatment of DMD.

Key words. Antisense oligonucleotides. Duchenne muscular dystrophy. Dystrophin. 